\title{
Gender Inequality in Education in China
}

\author{
Yuexuan $\mathrm{Li}^{1 *}$
}

\author{
${ }^{1}$ Yuexuan Li: Singapore American School \\ *juliegamer1213@gmail.com
}

\begin{abstract}
This paper investigates gender inequality in China. It includes, more specifically, research into gender inequality differences between rural and urban areas in order to compare them. In addition, this paper focuses on gender inequality in educational opportunities in China. Finally, the study delves into how gender inequality in China has evolved over time using reliable graphs and research, and discusses how educational opportunities for women and men in China have changed over the decades.
\end{abstract}

Keywords: Education, gender, inequality, men, women, rural, urban, fees.

\section{INTRODUCTION}

Educational investment is among the essential gift a child can get provided within this advanced world. Children should all be given an equal opportunity to try and learn without regard if they are male or female. The meta-regression analysis from different studies shows that there has been a decrease in the rate of gender inequality in education in China [11]. However, still, there is that percentage that is yet to be concurred and make education a center of all gender. Education is the key to success; hence all children should be given that key and fight for their success. Gender equality improves the productivity of the current generation and provides a good platform for the next. If all genders all be given equal opportunities, they will be living in better standards, greater social status, and increase economic growth. Gender inequality in education gets viewed as a key indicator of gender inequality.

Gender inequality in education mostly affects females [2]. The population of the female gender has increased rapidly in China, causing most families to choose who they should invest in their education. Families prioritize boys due to their belief that the male gender has a better understanding of education and is more respected than the girls in society, hence denying their girls that education opportunity. Other families in China believe that the girls do not need to be very educated since they can be married to wealthy and well-educated boys and live a good life. By doing this, they don't give the girl a chance to do what she would love to.
Despite the vast available evidence, the research findings on gender bias in China's educational system is still varied. Some studies state that there are still considerable discrepancies in admission to learning amongst females and males. For instance, utilizing a 0.95 per one thousand micro-sample from two thousand Chinese populace census, the study found that fewer females got admitted in compulsory learning in early 2000 [4]. However, other research indicates that gender bias in learning has enhanced. For instance, utilizing China's early 1990s populace census statistics, the study discovered no crucial gender gap in the shift to university in urban regions [10]. There still exist enormous variability between the assessments of gender bias in China's educational system, and according to some studies, it is still drastic.

This study aims to comprehend the progress made by China (if any) in minimizing gender bias in education. To successfully meet this aim, we have some particular goals. First, we obtain all the practical articles that have assessed gender bias in learning since the 1980s, concentrating precisely on gender bias in education success. The findings of this research will systematically get categorized and whirled into a database that will develop the basis of our research and will assist us in recognizing the mediums through which gender biases happens. In this manner, this paper could get deemed as a metaanalysis. In addition, we tabulate the research outcomes and record the essence of gender bias in educational achievement since 1980 to date (reform era). Finally, we deteriorate the overall outcomes and trace how gender bias in education alters through time, across areas, through grade level amongst minority kids and Han. 


\section{METHODOLOGY}

Meta-analysis utilizes statistics to interpret and clarify prior documented statistical analyses that investigate similar manifestations. Therefore, metaanalysis refers to the statistical analysis done on the survey outcomes of much practical research. In a metaanalysis, research exploring a specific subject get compiled, and each documented practical research becomes a single or more statement [1]. Meta-analysis enables the examination of the impact of the various data traits and methodologies of the outcomes documented. While this particular research design contains similar prevalent goals as a comprehensive research paper, it is hard to give a complete quantitative examination. The researcher possesses complete control and understanding of the research. Various literature review-founded review, several papers get omitted or not handled because of a comprehensive desire to refine notions and concentrate efforts. However, mete-analysis gets presumed to exclude the restraint of narrative statements. Researchers compile papers systematically, which is an approach purposively conducted to exclude the researcher's prejudice. As an outcome, meta-analysis gets deemed by some people as a more complex substitute to narrative conversations of the research. The metaanalysis approach is better since it provides analysis for the larger results from this case. Whereby, there has been a decrease in gender inequality in education since there are more educational institutions in China, even though not all families can send all their children to schools. If only there would be gender equality, there would be a chance for a safer and healthier community [7].

To obtain a new measurement of the practical gender inequality in learning research, we will utilize a metaanalysis design in this paper. The meta-analysis should get remembered that it expresses a relationship which associates with all researches. The connection among the autonomous and result variable should not indicate an informal connection. The connection established in the research amongst the variables may be because of an excluded variable prejudice. In addition, there could be heterogeneity with the research, which implies that we are only documenting the average outcomes. The reader requires to have these considerations when inferring the outcomes.

\section{LITERATURE REVIEW}

\subsection{Rural areas and gender bias in education}

Gender inequality in education is caused by many factors, including a rise in the market economy, which has negatively and positively affected the education sector. With the rise in the economy comes more slots in schools, but still, the money is needed, and with the economy rising, some families can't afford to pay the fees for all their children. Reports show that even though most families can send their children to elementary, primary and junior high school, they cannot send them to tertiary schools (González, et al., 2020). Another factor affecting gender inequality in education is the number of children in the household. In rural areas, over fifty per cent of the families have more than one child, and the family income is likely low to support the education of all the children; hence the families choose who should attend school and who shouldn't. It's mostly the girls in such a household that faces the consequence of not attending school since the gender bias against girls is too high compared to that of the boys, especially in the education sector. As in the table below, gender inequality is more pronounced along the lines of urban and rural areas in China.

Table 1. Gender inequality in education against girls in China

\begin{tabular}{|c|c|c|}
\hline & & $\begin{array}{c}\text { Percentage of } \\
\text { research } \\
\text { discovering } \\
\text { Gender } \\
\text { Inequality. }\end{array}$ \\
\hline & $1980 \mathrm{~s}$ & 81 \\
Time & $1990 \mathrm{~s}$ & 67 \\
\hline Area & $2000 \mathrm{~s}$ & 54 \\
\hline & Rural & 68 \\
Grade level & Urban & 36 \\
\hline & Elementary & 67 \\
Ethnicity & Upper secondary & 62 \\
& Tertiary & 71 \\
& Minority & 68 \\
\hline
\end{tabular}

[8]

In the urban areas, the possibility of a girl attaining education is higher since most households have just one child and even though the economy is higher, the education sector in urban areas is way much improved with a better system hence increasing the chances of an educated girl in well-known schools to secure a good employment opportunity [6]. In addition, the possibility of females attaining education in urban areas is high because the is less competition. The family setting of urban families is small with most families having one or two children; this provides a lesser competition in education, which provides females with higher opportunities in the education sector.

\subsection{Tuition fees causing gender bias in education}

The factor of tuition fees has played a bigger role in gender inequality in education. The tuition fee for a rural public high school in China is higher than that of most developing countries worldwide. Considering the family 
income of most families that are supposed to pay for college fees and expenses, which is likely to be twenty or more times the income, they wouldn't be in a position to afford that much. Even though different schools have different fees, and a student can find one that is affordable to their family income, there is still that need to join a well-known and recognized education institution whereby there is some guaranty that one will have a chance to secure a well-paying employment opportunity and have a chance to support the family (González, et al., 2020).

\subsection{Social classes and gender inequality}

China, one of the countries with social classes that affect gender inequality in education, gives us more reason to study this case. Families in the high social class have no problem taking their children to school and providing them with the equipment needed to focus on their education. This is not the case for all the medium social classes; they might be able to provide education to their children up to a certain level, especially when they are to join colleges; some medium social classes can't afford the tuition fee and the expenses. As for the lower social class, the girls are the ones who mostly pay the price of been poor since the families mostly choose boys to attend schools, which are then pushed to work very hard to attain a scholarship to join college (Li et at., 2019).

\subsection{Gender inequality in education causing earnings inequality}

Moreover, gender inequality in education has caused inequality in gender earnings. Even though a girl has worked hard in her education course and got the same employment opportunity as a boy with the same education level, it's most likely that the institution will accept the male. This is causing a lot of negative influence on the education sector, and the morale for girls to join schools and work hard to be employed is decreasing. Gender earnings inequality occurred when a boy got the opportunity to attend school, work hard and manage to get a well-paying job. In contrast, the girl, who only got a basic education and didn't manage to attend college, is likely to get a basic job. This creates the difference between what they are earning, but if the girl would have gotten the same opportunity as the boy, there is a possibility that they both would be earning the same [6]. It can therefore be said that the onset of education for boys and girls has a huge role in determining their earnings and pay in their successive jobs in the future. Basic education for girls have a long lasting impact on their future careers as their basic training will not take them far in their search for professional jobs. On the other hand, with boys getting a lot more training than the girls, they are bound to be better placed in their professional careers. Gender biased education and training therefore goes a long way to have a negative impact on the earnings made by girls. Inequality on pay and gender pay gap issues on the other hand also affects the level of education attained by the girls. With existing glaring issues on pay gap, the girls are demoralized to get educational training as they will be presented with unequal opportunities at the labor market.

\subsection{Lagged economic growth}

Another instance is reduced economic growth, which is caused by gender inequality in education. With the rate of girls not acquiring education, the rate of unemployment also goes up, which negatively affects China's economic growth. There is a need for both genders to attend schools and acquire knowledge; this increases the possibility of acquiring employment which improves the living standards of most. While girls are the ones who are mostly denied education, especially those in rural areas, this affects the growth of the economy since they don't have the means to pay taxes. The rate of dependence is still increasing as they get married; hence the husband is the provider [3]. Most common in rural areas, the girls do have access to proper educational training hat goes on to affect their chances of having job opportunities. The labor market is competitive and therefore with basic education, they do not stand a chance with the more educated boys Without job opportunities as from poor educational background, they are not able to provide from themselves, where their economic burden is transferred to others who are economically well off with the numbers of females in the labor force in the past ten years having gone down as in the graph below.

Graph 1: Lower levels of working women in China making up the labor force.

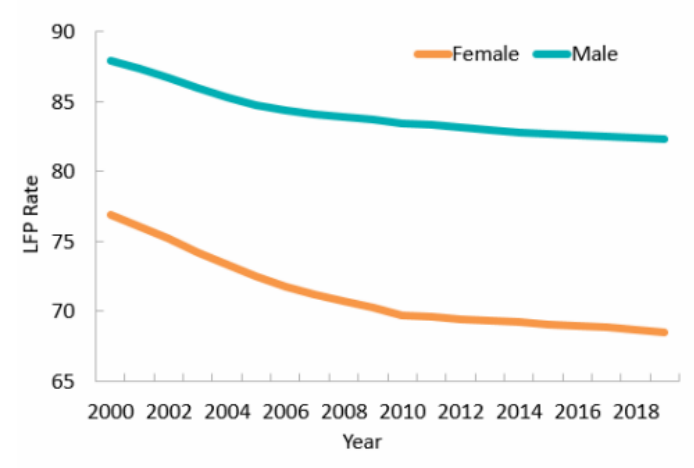

This could lead to a financial strain on those in the labor market which overall affects the economy of the country. The country could also be in a better position with more of the female gender in the working population. The economy is therefore hurt when part of the population is dependent on the labor working class where the resources could be diverted to income earning activities and where the country is missing out on economic 
activities that could have otherwise be carried out by the non-working female gender.

\subsection{Compulsory schooling in urban areas}

The rate of less-educated mothers has decreased from the analysis its quite convenient to say that there have been more education facilities in modern China, especially in urban areas. It is a far cry from the educational training in rural China where education bias can still be observed. More opportunities on education in urban areas have ensured that children of both genders are equally educated up to junior high school. There has been a more intellectually stimulating environment since education became compulsory for the first nine years of primary and junior high school. Having compulsory education has done away with bias in education where students have to attend classes, their gender notwithstanding. Women can contribute to answering educational questions since they have some knowledge acquired while at school compared to the 1980s when women were not educated. The use of the metaregression analysis approach has aided in providing a review of the gender educational differences.

\subsection{Greater gender bias in rural areas}

Analysis shows that the most affected areas in China are the rural areas. The urban areas are more advanced in technology, and both genders are given opportunities to attend schools. China has been an interesting case because of its extremely fast, rising economy, yet it's been unequal between urban and rural, especially o the education front. The growth in urban areas has rapidly increased with advanced technology, where the rural area is left behind; this result results in the rural area's education also being left behind. As education does not improve in rural areas, it raises gender inequality in education since some have to be prioritized. It is a glaring issue that rural China is facing as unequal education opportunities are far reaching in their negative consequences especially to girls on unequal job opportunities and consecutively gender bias issues in terms of wage gap.

Graph 2: Comparison of Girls and Boys across three dimensions in China

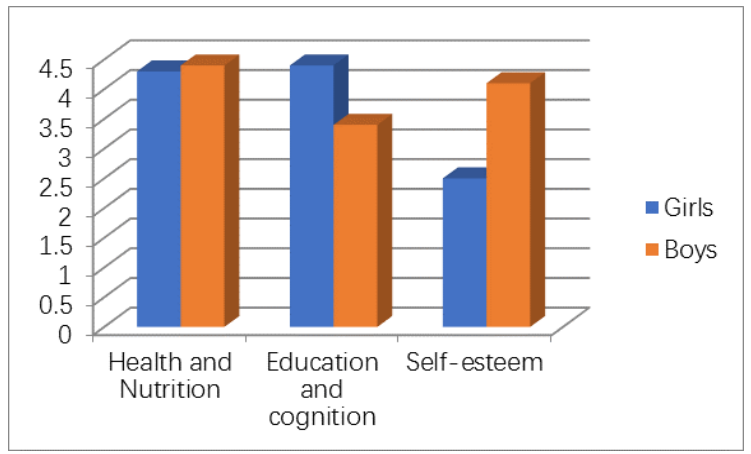

This graph displays that girls have similar health and nutritional results as boys. In academics, the data shows that girls perform better than their male counterparts. However, the gender gap is still evident concerning noncognitive results. Females in this sample display a relatively low-esteem and anxiety than boys. In addition, analysis displays that overall the results are vigorous; the evidence concerning the reduction in gender gap in China is not profound to the elimination of relatively older and younger pupils from the sample. Additionally, the evidence is not profound to the level of domestic resources or regional heterogeneity. These robustness displays further proposes that the gender gap found in China has certainly become modest.

\section{CONCLUSION}

Discrimination against girls still exists in modern China. However, reports show that there has been a decrease in the trend over time. From the 1980s, 1990s and 2000s, girl's access to education has increased as per China's economic development. Differences in gender education differ between rural and urban areas. The most glaring education bias in modern china occurs on whether students come from rural or urban areas. This further translates to issues on gender disparity in education access. In urban areas, the girls have easy access to educational facilities and can attend schools; hence there is less or no gender inequality in education. They have equal opportunities for educational training as the boys do as with mandatory schooling for children up to junior high school. As for the rural areas, it seems as if the girls pay for living in the rural. Even though there is no gender inequality in the compulsory education setup, gender is still valued in education. Girls are less in the higher education centers since the boys are prioritized, especially from the senior school. Despite girls facing gender inequality, the analysis shows that they don't seem to face demerits in school performance. Mostly it's the girls who strive in education than the boys.

\section{AUTHORS' CONTRIBUTIONS}

All research was conducted and written by Yuexuan Li. I read and approve of the final manuscript.

\section{ACKNOWLEDGMENTS}

Special thanks to Professor Shamus Khan (Princeton University) for his generous assistance in the preparation of this paper.

\section{REFERENCES}

[1] Balduzzi, S., Rücker, G., \& Schwarzer, G. (2019). How to perform a meta-analysis with R: a practical tutorial. Evidence-based mental health, 22(4), 153160. 
[2] Fincher, L. H. (2016). Leftover women: The resurgence of gender inequality in China. Zed Books Ltd.

[3] González, A. V., Barrett, M., Hvingelby, R., Webster, K., \& Søgaard, A. (2020). Type B reflexivization as an unambiguous testbed for multilingual multi-task gender bias. arXiv preprint arXiv:2009.11982.

[4] Gooch, E. (2019). Terrain ruggedness and limits of political repression: Evidence from China's Great Leap Forward and Famine (1959-61). Journal of Comparative Economics, 47(4), 827-852.

[5] Li, J., Zhang, J., Zhang, D., \& Ji, Q. (2019). Does gender inequality affect household green consumption behaviour in China?. Energy Policy, 135, 111071.

[6] Prates, M. O., Avelar, P. H., \& Lamb, L. C. (2020). Assessing gender bias in machine translation: a case study with google translate. Neural Computing and Applications, 32(10), 6363-6381.

[7] Suurmond, R., van Rhee, H., \& Hak, T. (2017). Introduction, comparison, and validation of Meta Essentials: a free and simple tool for meta analysis. Research synthesis methods, 8(4), 537553.

[8] Churchill, S. A., \& Mishra, V. (2018). Returns to education in China: a meta-analysis. Applied Economics, 50(54), 5903-5919.

[9] Lund, A. C. (2020). The One Child Policy: A Moral Analysis of China's Most Extreme Population Policy.

[10] Ye, T., Zhao, N., Yang, X., Ouyang, Z., Liu, X., Chen, Q., ... \& Jia, P. (2019). Improved population mapping for China using remotely sensed and points-of-interest data within a random forests model. Science of the total environment, 658, 936946.

[11] Zeng, J., Pang, X., Zhang, L., Medina, A., \& Rozelle, S. (2014). Gender inequality in education in China: a meta - regression analysis. Contemporary Economic Policy, 32(2), 474-491. 